\title{
Distinct magnetic resonance imaging features in a patient with novel RARS2 mutations: A case report and review of the literature
}

\author{
JIE ZHANG, ZHONGBIN ZHANG, YAO ZHANG and YE WU \\ Department of Pediatrics, Peking University First Hospital, Beijing 100034, P.R. China
}

Received December 16, 2016; Accepted July 14, 2017

DOI: $10.3892 /$ etm.2017.5491

\begin{abstract}
Pontocerebellar hypoplasia type 6 (PCH6) is a rare autosomal recessive disease that occurs due to mutations in the mitochondrial arginyl-tRNA synthetase 2 (RARS2) gene. To the best of our knowledge, 23 cases with relatively complete clinical data have been reported thus far. In the present study, a case with PCH6 caused by novel RARS2 mutations is described, in which distinct magnetic resonance imaging (MRI) features were identified. In addition, 23 PCH6 cases found in the literature were reviewed. Early onset hypotonia (43.48\%), epileptic seizures (34.78\%), encephalopathy (26.08\%) and feeding difficulties (17.39\%) were common initial symptoms of PCH6. During disease progression, the patients presented refractory epileptic seizures $(94.12 \%)$, feeding problems $(60.87 \%)$, severe developmental delay (100\%), microcephaly $(88.89 \%)$ and hyperlactacidemia $(76.47 \%)$. The clinical features of the present patient were suggestive of PCH6, with early onset epilepsy, feeding difficulties, severe developmental delay, microcephaly, hearing loss and hyperlactacidemia. According to available MRI data from 20 reported cases with PCH6, the characteristic finding in MRI was pontocerebellar dysplasia or progressive cerebral/pontocerebellar atrophy in 16 cases, while 4 cases did not present pontocerebellar hypoplasia, and no basal ganglia involvement was observed in any of the cases. Distinctive MRI features were also identified in the present case, including pontocerebellar preservation after 1 year of age, as well as a high diffusion-weighted imaging signal suggesting intracellular edema in the cerebellar hemispheres, basal ganglia, thalamus and corpus callosum. Progressive loss of cerebral white matter and cortical volume were common features shared by all patients. In conclusion, in the present study, two novel heterozygous mutations were identified in $R A R S 2$, namely c.1718C $>\mathrm{T}$ (p.Thr573Ile) and c.991A $>$ G (p.Ile331Val). Thus, the present case enriched the phenotypic and genotypic spectrum of the RARS2 mutations.
\end{abstract}

Correspondence to: Dr Ye Wu, Department of Pediatrics, Peking University First Hospital, 1 Xi An Men Street, Beijing 100034, P.R. China

E-mail: dryewu@263.net

Key words: RARS2, pontocerebellar hypoplasia type 6, magnetic resonance imaging

\section{Introduction}

The mitochondrial arginyl-tRNA synthetase 2 (RARS2) encodes the mitochondrial arginyl-transfer RNA synthetase (1), which is essential for the translation of all proteins synthesized in the mitochondria. In 2007, mutations in RARS2 were first identified in pontocerebellar hypoplasia type 6 (PCH6; MIM no. 611523) with autosomal recessive inheritance (2). To the best of our knowledge, 23 cases with RARS 2 mutations have been reported in the literature thus far (1-11). PCH6 is a rare mitochondrial disease. The age of disease onset varies from birth $(6,11,14,15)$ to 9 months old $(8)$. The common initial symptoms of mitochondrial disease include hypotonia $(1,2,4,6-8)$, epileptic seizures $(5,6,8,9,11)$, encephalopathy $(1,2,4,6,10)$ and feeding difficulties $(2,3)$. Furthermore, other uncommon initial presentations have been suggested, including hypoglycemia $(6,11)$, tachypnea $(2,10)$ and cyanosis (7). Almost all patients developed early-onset epileptic seizures $(1-3,5,6,9,11)$ and the age of onset may vary from 1 day (5) to 9 months old (8). Seizures have been typically described as intractable to a variety of antiepileptic drugs. In addition, feeding difficulties have been suggested a prominent problem in the patients with PCH6 $(1-6,8,11)$ and some cases have been diagnosed with gastroesophageal reflux $(3,6)$. The majority of patients have presented with severe developmental delay $(1-3,5,6,8,9,11)$ and microcephaly (1-6,8-11). Hyperlactacidemia has also been determined a common clinical feature in PCH6 (1-3,5-7,11). Additionally, hearing loss and optic atrophy have been observed in some cases $(1,8)$. The most characteristic finding in magnetic resonance imaging (MRI) is early onset or progressive cerebral/pontocerebellar atrophy $(1-3,5-8,11)$. Furthermore, one case has been reported with subdural effusions in MRI (7).

In the present study, a PCH6 case with distinctive MRI presentations in an infant was reported. In addition, the characteristics of previous published cases of PCH6 in the literature were reviewed. The present case enriched the phenotypic and genotypic spectrum of the RARS 2 mutations.

\section{Case report}

Case. The present case involves a boy at the age of 3 months that presented at the Peking University First Hospital (Beijing, China) at September, 2014 with complaint of frequent convulsions. The patient was a full-term infant (birth 
weight, 2,250 g) with non-consanguineous parents, and failed a neonatal hearing screening. Frequent multifocal myoclonic seizures and focal seizures were reported, which began at the age of 3 months. The patient did not respond to antiepileptic drug treatment for the seizures, including valproic acid, levetiracetam, topiramate, phenobarbital and clonazepam. Ketogenic diet therapy was attempted; however, this was stopped due to poor tolerance. The infant gradually presented with hypotonia and feeding difficulty from 5 months of age, lethargy and progressive microcephaly from 7 months of age.

Hyperlactacidemia was determined from blood samples with the range of 3.2-9.5 mmol/1 (normal range is $0 \sim 2.5 \mathrm{mmol} / \mathrm{l}$ ), which was observed since 4 months of age. An electroencephalogram at the age of 6 months demonstrated diffuse slow waves mixed with multifocal spikes and fast waves in the two hemispheres, with persistent focal seizures observed during the monitoring. An auditory brainstem response test at the age of 4 months revealed no response to the stimulus with an intensity of $100 \mathrm{db}$.

Serial brain MRI scans were performed at 4, 5, 7 and 13 months after birth, respectively (Fig. 1). Various distinctive features were observed in these scans, whereas pontocerebellar dysplasia or atrophy was absent. A high diffusion-weighted imaging (DWI) signal was detected in the frontal and parietal cerebral cortex at 4 and 5 months, which resolved after 7 months. The cortex edema was possibly associated with the frequent multifocal seizures at that time. From 5 months of age, a high signal was present on T2-weighted image (T2WI) and DWI scans in the basal ganglia and thalamus, followed by progressive atrophy. At 7 months, a symmetric high signal was detected on DWI in bilateral cerebellar hemispheres, which was suggestive of intracellular edema. In addition, in the 7-month scan, atrophy of the cerebral cortex became prominent with concomitant subdural effusions, while high DWI signals were observed in the genu and splenium of the corpus callosum, concomitant with progressive white matter depletion.

On the basis of the refractory seizures, encephalopathy, hyperlactacidemia and special MRI features, the patient was suspected with the diagnosis of early epileptic encephalopathy and mitochondrial disease since his 9 months. He received gene analysis at the age of 9 months, which included analysis of common mitochondrial nuclear genes.

Genomic DNA was isolated from peripheral leukocytes, fragmented into 150-200 bp length and sonicated. The DNA fragments were then processed by end-repairing, A-tailing and adaptor ligation, a 4-cycle pre-capture PCR amplification and enriched by a custom-designed panel capturing the coding exons of 256 genes associated with mitochondrial nuclear genes, including $R A R S 2$. Paired-end sequencing (150 bp) was performed on Illumina HiSeq X-ten platform to provide a mean sequence coverage of $>$ x 100, with $>95 \%$ of the target bases having at least $x 20$ coverage. Raw data was processed by the Illumina pipeline (version 1.3.4) for image analysis, error estimation, base calling and generating the primary sequence data. For the quality control, the Cutadapt (https://pypi.python.org/pypi/cutadapt) and FastQC (www. bioinformatics.babraham.ac.uk/projects/fastqc/) were used to remove 3 '-/5'-adapters and low-quality reads, respectively. The clean reads were mapped to the human reference genome
(UCSC hg19) with the use of the BWA (version 0.7.10, http://bio-bwa.sourceforge.net) (12), duplicate sequence reads were removed by Picard (version 1.85; http://picard. sourceforge.net), and GATK (version 3.1, https://software. broadinstitute.org/gatk/) (13) was used to detect variants. Variants were annotated using ANNOVAR software (http://www.openbioinformatics.org/annovar/) as described previously (14), which included function implication (gene region, functional effect, mRNA GenBank accession number, amino acid change and cytoband) and allele frequency in several databases: dbSNP138, 1000 Genomes (Phase 3-Variant Frequencies 5b), ExAc (exac.broadinstitute.org/) as described previously (15). Damaging missense mutations were predicted by SIFT (sift.bii.a-star.edu.sg/), PolyPhen-2 (genetics.bwh. harvard.edu/pph2/), and MutationTaster (www.mutationtaster. org/). Interpretation of the variants was conducted according to the American College of Medical Genetics and Genomics recommended standards (16), and all the variants were categorized into 'pathogenic', 'likely pathogenic', 'uncertain significance', 'likely benign' and 'benign'. Sanger sequencing was performed to validate the putative pathogenic variants and segregation analyses where possible.

Novel compound heterozygous mutations in $R A R S 2$, namely c.1718C >T(p.Thr573Ile) and c.991A $>$ G(p.Ile331Val), were identified in the patient. SIFT (sift.bii.a-star.edu.sg/) and Mutation Taster (www.mutationtaster.org/) predicted that these mutations would affect the protein function (Table I). At the age of 10 months, the patient was diagnosed with PCH6 due to RARS2 mutations.

The last follow-up was performed when the patient was 3 years old. The patient was receiving nasogastric feeding, while severe developmental delay, rigidity and loss of response to external stimuli were reported. The seizures were partially managed by combination therapy with topiramate ( $4 \mathrm{mg} / \mathrm{kg} /$ day) and levetiracetam $(42 \mathrm{mg} / \mathrm{kg} /$ day).

Written informed consent was obtained from the patient's family for the publication of the present case study.

Literature review. The databases PubMed (https://www.ncbi. nlm.nih.gov/pubmed), EMbase (http://www.embase.com), CBM (http://www.sinomed.ac.cn/), CNKI (http://www.cnki. net/) and VIP (http://lib.cqvip.com/) were searched to collect studies with the key words of 'RARS2' and 'PCH6', date from database foundation to December, 2016. The publication language was limited to English and Chinese. Studies reported of cases with PCH6, which include detailed clinical data were included in the present study.

\section{Discussion}

Since the identification of RARS2 mutations in PCH6 in 2007 (2), a total of 23 cases with $R A R S 2$ mutations have been reported in 11 studies (1-11), as identified according to a literature review performed in the present study. The clinical features of the reported cases are summarized in Table II.

In these previously reported $\mathrm{PCH} 6$ cases, the age of disease onset was 1 day to 9 months. In $52.17 \%$ (12/23) of cases symptoms were detected on the first day of life, while disease onset was observed between 1 day and 1 month of age in $26.09 \%(6 / 23)$ of cases, between 1 month and 3 months of age 
Table I. RARS2 mutations in patients with PCH6 in the present and previous studies.

\begin{tabular}{|c|c|c|c|c|}
\hline Patient & Mutation location & Nucleotide change & Amino acid change & (Refs.) \\
\hline 1 & $\begin{array}{l}\text { Exon14 } \\
\text { Exon7 }\end{array}$ & $\begin{array}{l}\text { c. } 1211 \mathrm{~T}>\mathrm{A} \\
\text { c.472_474delAAA }\end{array}$ & $\begin{array}{l}\text { p.Met404Lys } \\
\text { p.Lys158del }\end{array}$ & (1) \\
\hline 2 & $\begin{array}{l}\text { Intron2 } \\
\text { Exon1 }\end{array}$ & $\begin{array}{l}\text { c. } 110+5 \mathrm{~A}>\mathrm{G} \\
\text { c. } 35 \mathrm{~A}>\mathrm{G}\end{array}$ & p.Gln12Arg & (2) \\
\hline 3 & $\begin{array}{l}\text { Intron2 } \\
\text { Exon1 }\end{array}$ & $\begin{array}{l}\text { c. } 110+5 \mathrm{~A}>\mathrm{G} \\
\text { c. } 35 \mathrm{~A}>\mathrm{G}\end{array}$ & p.Gln12Arg & (2) \\
\hline 4 & $\begin{array}{l}\text { Intron2 } \\
\text { Exon1 }\end{array}$ & $\begin{array}{l}\text { c. } 110+5 \mathrm{~A}>\mathrm{G} \\
\text { c. } 35 \mathrm{~A}>\mathrm{G}\end{array}$ & p.Gln12Arg & (2) \\
\hline 5 & $\begin{array}{l}\text { Exon12 } \\
\text { Exon1 }\end{array}$ & $\begin{array}{l}\text { c. } 1024 \mathrm{~A}>\mathrm{G} \\
\text { c. } 35 \mathrm{~A}>\mathrm{G}\end{array}$ & $\begin{array}{l}\text { p.Met342 Val } \\
\text { p.Gln12Arg }\end{array}$ & (3) \\
\hline 6 & $\begin{array}{l}\text { Intron2 } \\
\text { Exon1 }\end{array}$ & $\begin{array}{l}\text { c. } 110+5 \mathrm{~A}>\mathrm{G} \\
\text { c. } 35 \mathrm{~A}>\mathrm{G}\end{array}$ & $\begin{array}{l}- \\
\text { p.Gln12Arg }\end{array}$ & (4) \\
\hline 7 & $\begin{array}{l}\text { Exon10 } \\
\text { Intron19 }\end{array}$ & $\begin{array}{l}773 \mathrm{G}>\mathrm{A} \\
\text { c. } 1651-2 \mathrm{~A}>\mathrm{G}\end{array}$ & p.Arg258His & (5) \\
\hline 8 & $\begin{array}{l}\text { Exon10 } \\
\text { Intron19 }\end{array}$ & $\begin{array}{l}773 \mathrm{G}>\mathrm{A} \\
\text { c. } 1651-2 \mathrm{~A}>\mathrm{G}\end{array}$ & p.Arg258His & (5) \\
\hline 9 & $\begin{array}{l}\text { Exon1 } \\
\text { Intron18 }\end{array}$ & $\begin{array}{l}\text { c. } 25 \mathrm{~A}>\mathrm{G} \\
\text { c. } 1586+3 \mathrm{~A}>\mathrm{T}\end{array}$ & $\begin{array}{l}\text { p.Ile9Val } \\
-\end{array}$ & (6) \\
\hline 10 & $\begin{array}{l}\text { Exon1 } \\
\text { Intron18 }\end{array}$ & $\begin{array}{l}\text { c. } 25 \mathrm{~A}>\mathrm{G} \\
\text { c. } 1586+3 \mathrm{~A}>\mathrm{T}\end{array}$ & $\begin{array}{l}\text { p.Ile9Val } \\
-\end{array}$ & (6) \\
\hline 11 & $\begin{array}{l}\text { Exon9 } \\
\text { Exon16 }\end{array}$ & $\begin{array}{l}\text { c. } 734 \mathrm{G}>\mathrm{A} \\
\text { c. } 1406 \mathrm{G}>\mathrm{A}\end{array}$ & $\begin{array}{l}\text { p.Arg245Gln } \\
\text { p.Arg469His }\end{array}$ & (6) \\
\hline 12 & $\begin{array}{l}\text { Exon9 } \\
\text { Exon16 }\end{array}$ & $\begin{array}{l}\text { c. } 734 \mathrm{G}>\mathrm{A} \\
\text { c. } 1406 \mathrm{G}>\mathrm{A}\end{array}$ & $\begin{array}{l}\text { p.Arg245Gln } \\
\text { p.Arg469His }\end{array}$ & (6) \\
\hline 13 & $\begin{array}{l}\text { Exon9 } \\
\text { Exon1 }\end{array}$ & $\begin{array}{l}\text { c. } 721 \mathrm{~T}>\mathrm{A} \\
\text { c. } 35 \mathrm{~A}>\mathrm{G}\end{array}$ & $\begin{array}{l}\text { p.Trp241Arg } \\
\text { p.Gln12Arg }\end{array}$ & (6) \\
\hline 14 & $\begin{array}{l}\text { Exon1 } \\
\text { Intron8 }\end{array}$ & $\begin{array}{l}\text { c. } 1 \mathrm{~A}>\mathrm{G} ; \\
\text { c.613-3927C }>\mathrm{T}\end{array}$ & p.Met1 Val & (7) \\
\hline 15 & $\begin{array}{l}\text { Exon1 } \\
\text { Intron8 }\end{array}$ & $\begin{array}{l}\text { c. } 1 \mathrm{~A}>\mathrm{G} \\
\text { c. } 613-3927 \mathrm{C}>\mathrm{T}\end{array}$ & $\begin{array}{l}\text { p.Met1Val } \\
-\end{array}$ & (7) \\
\hline 16 & $\begin{array}{l}\text { 5'-UTR } \\
\text { 5'-UTR }\end{array}$ & $\begin{array}{l}\text { c. }-2 A>G \\
\text { c. }-2 A>G\end{array}$ & $\begin{array}{l}- \\
-\end{array}$ & (8) \\
\hline 17 & $\begin{array}{l}\text { 5'-UTR } \\
\text { 5'-UTR }\end{array}$ & $\begin{array}{l}\text { c. }-2 A>G \\
\text { c. }-2 A>G\end{array}$ & $\begin{array}{l}- \\
-\end{array}$ & (8) \\
\hline 18 & $\begin{array}{l}\text { Intron2 } \\
\text { Intron10 }\end{array}$ & $\begin{array}{l}\text { c. } 110+5 \mathrm{~A}>\mathrm{G} \\
\text { c. } 878+5 \mathrm{G}>\mathrm{T}\end{array}$ & $\begin{array}{l}- \\
-\end{array}$ & (9) \\
\hline 19 & $\begin{array}{l}\text { Intron2 } \\
\text { Intron10 }\end{array}$ & $\begin{array}{l}\text { c. } 110+5 \mathrm{~A}>\mathrm{G} \\
\text { c. } 878+5 \mathrm{G}>\mathrm{T}\end{array}$ & $\begin{array}{l}- \\
-\end{array}$ & (9) \\
\hline 20 & $\begin{array}{l}\text { Exon5 } \\
\text { Exon5 }\end{array}$ & $\begin{array}{l}\text { c. } 392 \mathrm{~T}>\mathrm{G} \\
\text { c. } 392 \mathrm{~T}>\mathrm{G}\end{array}$ & $\begin{array}{l}\text { p.Phe131Cys } \\
\text { p.Phe131Cys }\end{array}$ & $(10)$ \\
\hline 21 & $\begin{array}{l}\text { Exon5 } \\
\text { Exon5 }\end{array}$ & $\begin{array}{l}\text { c. } 392 \mathrm{~T}>\mathrm{G} \\
\text { c. } 392 \mathrm{~T}>\mathrm{G}\end{array}$ & $\begin{array}{l}\text { p.Phe131Cys } \\
\text { p.Phe131Cys }\end{array}$ & $(10)$ \\
\hline 22 & $\begin{array}{l}\text { Exon7 } \\
\text { Exon10 }\end{array}$ & $\begin{array}{l}\text { c. } 472 \_474 \text { delAAA } \\
\text { c. } 848 \mathrm{~T}>\mathrm{A}\end{array}$ & $\begin{array}{l}\text { p.Lys158del } \\
\text { p.Leu283Glu }\end{array}$ & (11) \\
\hline 23 & $\begin{array}{l}\text { Exon7 } \\
\text { Exon10 }\end{array}$ & $\begin{array}{l}\text { c. } 472 \_474 \text { delAAA } \\
\text { c. } 848 \mathrm{~T}>\mathrm{A}\end{array}$ & $\begin{array}{l}\text { p.Lys 158del } \\
\text { p.Leu283Glu }\end{array}$ & (11) \\
\hline Present case & $\begin{array}{l}\text { Exon20 } \\
\text { Exon12 }\end{array}$ & $\begin{array}{l}\text { c. } 1718 \mathrm{C}>\mathrm{T} \\
\text { c. } 991 \mathrm{~A}>\mathrm{G}\end{array}$ & $\begin{array}{l}\text { p.Thr573Ile } \\
\text { p.Ile331Val }\end{array}$ & \\
\hline
\end{tabular}




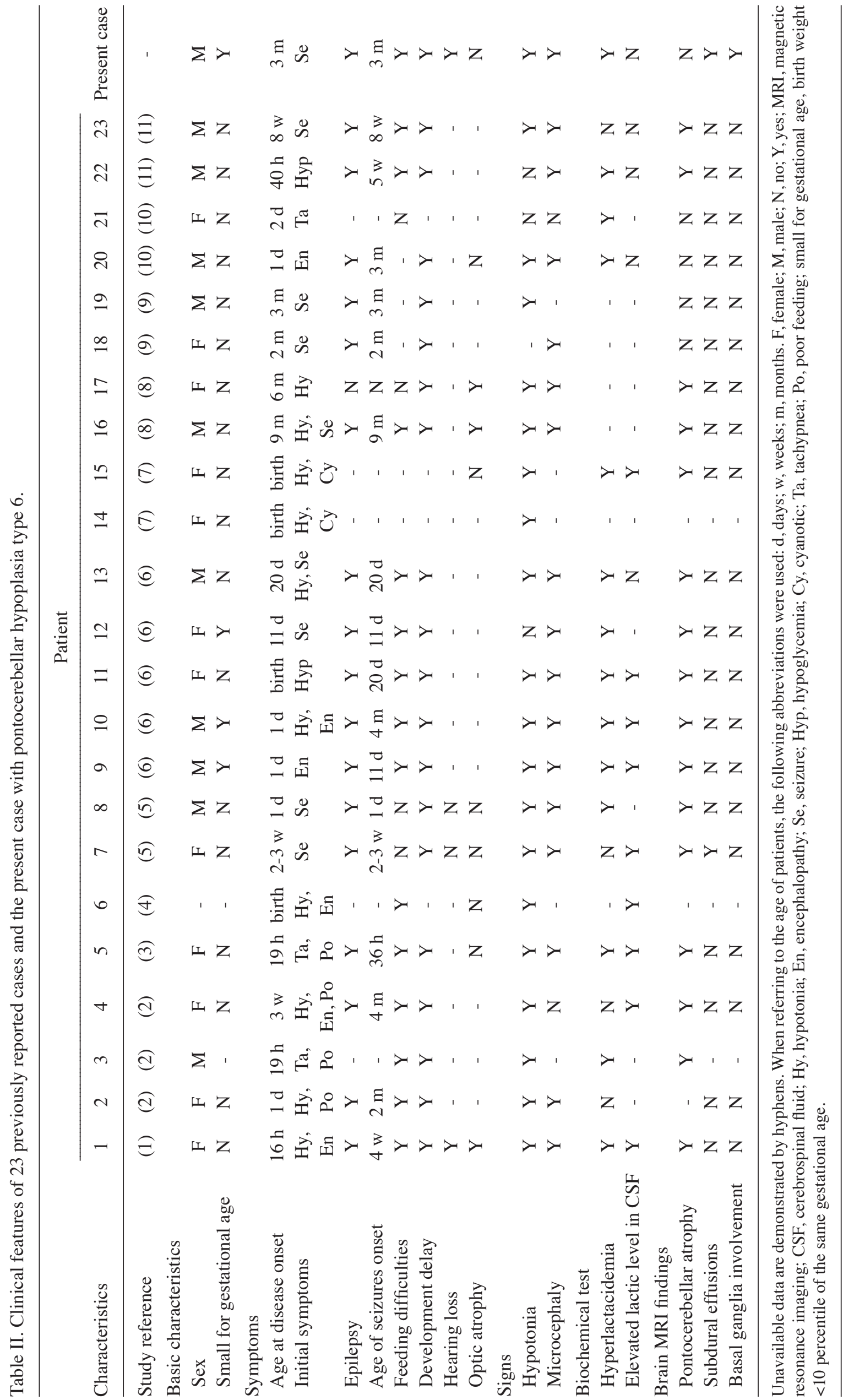



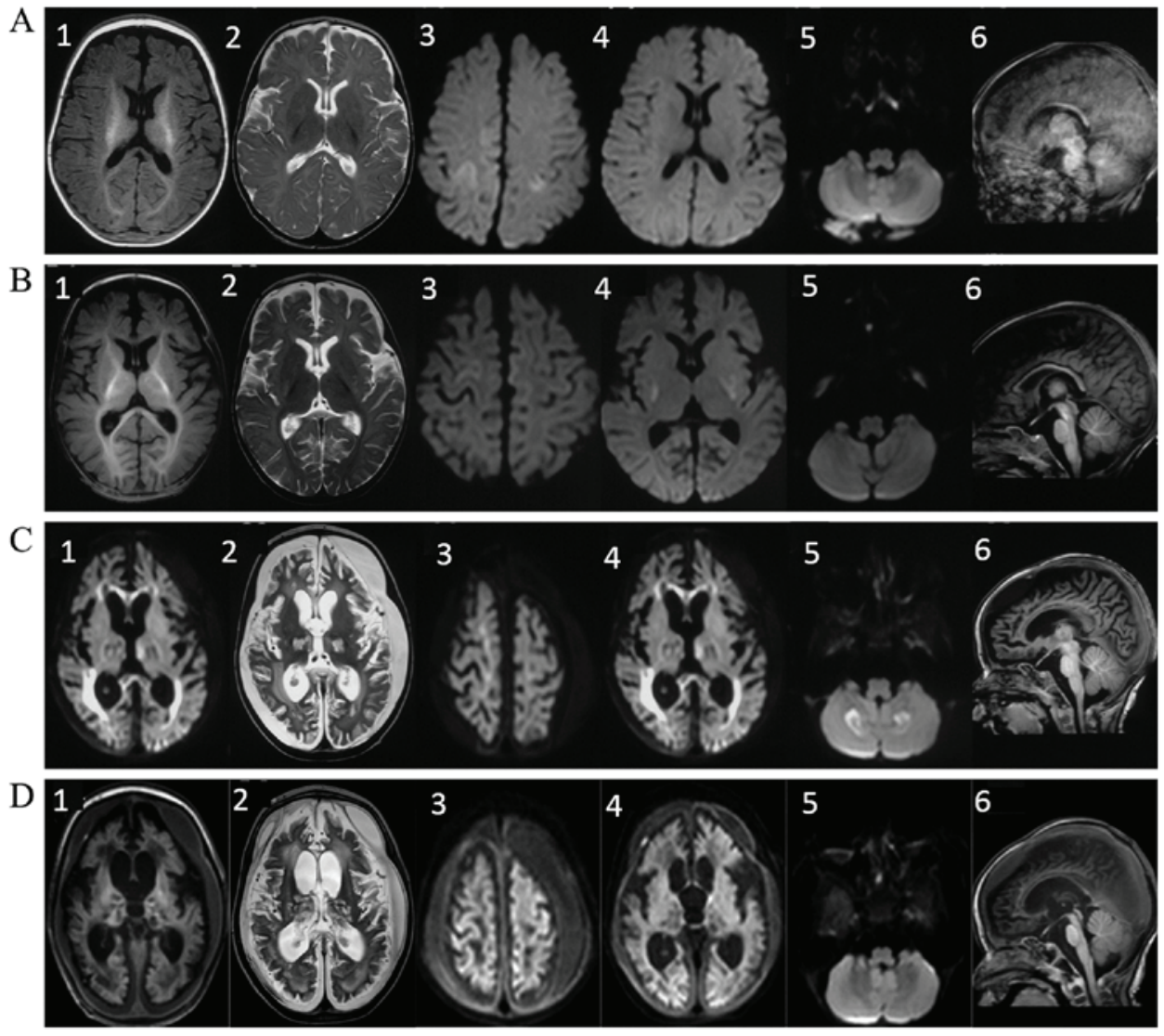

Figure 1. Serial brain MRI scans performed in the present case. MRI scanning was performed at (A) 4 months, (B) 5 months, (C) 7 months and (D) 13 months after birth. The images show the axial T1WI (labeled as 1), axial T2WI (labeled as 2), axial DWI in the frontal and parietal cerebral cortex (labeled as 3 ), axial DWI in the basal ganglia and thalamus (labeled as 4), axial DWI in the cerebellar hemispheres (labeled as 5) and sagittal T1WI scans (labeled as 6). The following distinctive features were observed in the MRI scans: i) Absence of pontocerebellar dysplasia or atrophy was absent (A6, B6, C6 and D6); ii) symmetric high signal was observed on the DWI scan in the bilateral cerebellar hemispheres at 7 months of age (C5), which was suggestive of intracellular edema; iii) a high DWI signal was observed in the frontal and parietal cerebral cortex at 4 months (A3), which resolved after 7 months of age (C3); iv) atrophy of the cerebral cortex became prominent at 7 months of age, with concomitant subdural effusions (C1, C2, D1 and D2) and v) high T2WI and DWI signals were observed in the basal ganglia and thalamus at 5 months (B4), followed by progressive atrophy (C4 and D4). vi) A high DWI signal was detected in the genu and splenium of the corpus callosum at 7 months (C4), concomitant with progressive white matter depletion (C1-3 and D1-3). MRI, magnetic resonance imaging; WI, weighted image; DWI, diffusion-weighted imaging.

in $13.04 \%(3 / 23)$ and after 6 months in $8.70 \%(2 / 23)$ of cases. The initial presentations included symptoms of hypotonia $(43.48 \%$; 10/23), epileptic seizures $(34.78 \%$; 8/23), encephalopathy $(26.08 \%$; 6/23) and feeding difficulties $(17.39 \% ; 4 / 23)$. Other uncommon initial presentations were hypoglycemia $(8.70 \% ; 2 / 23)$, tachypnea $(13.04 \% ; 3 / 23)$ and cyanosis $(8.70 \%$; $2 / 23$ ). Patients often presented with more than one initial symptom. In the present study, the initial presentation of the patient was epileptic seizures, which began at the age of 3 months.

With the exception of 4 cases of neonatal mortality and 1 patient with an age of 2 months at the last follow-up, almost all patients $(94.44 \%$; 17/18) developed early-onset epileptic seizures. The age of onset of refractory epilepsy was 1 day to 9 months, and seizures were usually intractable to a variety of antiepileptic drugs. Furthermore, 14 cases $(60.87 \%$; 14/23) presented feeding difficulties subsequent to birth or in the process of the follow-up. Of the included cases, 2 patients were unavailable for evaluation due to mortality within 2 weeks after birth, while information regarding feeding was unavailable in 3 cases. In total, 6 patients were diagnosed with gastroesophageal reflux, whereas 4 patients presented no feeding problems until the last follow-up conducted at 2 months, 1, 1.5 and 3 years of age, respectively. The present case also presented severe feeding difficulty and required nasogastric feeding subsequent to the disease onset.

The majority $(82.61 \% ; 19 / 23)$ of included cases presented severe developmental delay, with the exception of 3 cases of mortality within 14 days (at 14 days of age) and 1 patient with a last follow-up at the age of 2 months, who were unavailable for assessment. In addition, with the exception of 4 cases of mortality within 1 day to 7 weeks (aged 7 weeks old) and unavailable information of head circumference in 1 case, microcephaly was observed in $88.89 \%$ (16/18) of patients. Only 2 cases had a normal head circumference until the age of 2 and 4 months, respectively, which were the last follow-up times.

Mortality was reported in 6 (6 cases succumbed to fatality at 1, 14 day, 7 weeks, 16 months, 6 days and 4 years) out of 23 patients in the previous studies included in this literature review. In 1 case, mortality was reported on the first day following birth, between 6 days to 2 months in 3 patients, and at 16 months and 4 years in 2 other patients. In total, $73.91 \%(17 / 23)$ were alive at the last follow-up, with an age of 2 months to 11 years. 
Hyperlactacidemia was identified in $76.47 \%$ (13/17) of cases among 17 patients with available data. Other clinical features included hearing loss that was reported in $4.35 \%(1 / 23)$ cases and optic atrophy identified in $13.04 \%(3 / 23)$. The clinical features of the present patient were suggestive of PCH6, with early-onset epilepsy, feeding difficulty, severe developmental delay, microcephaly, hearing loss and hyperlactacidemia.

The characteristic finding in MRI was pontocerebellar dysplasia or progressive cerebral/pontocerebellar atrophy and in the majority of patients $(80.00 \%, 16 / 20)$ were observed with this feature. Compared with the available MRI data from 20 reported cases with PCH6, certain distinct MRI features were noted in the patient of the present study. No pontocerebellar dysplasia or atrophy was observed prior to 1 year of age in the present patient. In the previously reported 20 patients with available MRI data, 4 cases did not present pontocerebellar dysplasia/atrophy when tested at 10 days (10), 13 months (9), 16 months (9) and 40 months (10), respectively. By contrast, pontocerebellar dysplasia/atrophy were present in 16 cases, with $25 \%(4 / 16)$ in the neonatal stage, $43.75 \%$ (7/16) between 1 and 6 months, 18.75\% (3/16) between 1 and 9 months, and $12.5 \%$ (2/16) between 1-24 months (with a long interval between the two MRI examinations). The last brain MRI scan of the present study patient was performed at 13 months, therefore it does not exclude that pontocerebellar atrophy may have occurred at a later time.

MRI examination in the present patient also demonstrated high signals on T2WI and DWI scans in the cerebral cortex, cerebellar hemispheres, basal ganglia and thalamus. Notably, as PCH6 is an encephalopathy resulting from mitochondrial functional defect, basal ganglia involvement has not been reported in any previous patients with PCH6. Another MRI feature in the current study involves atrophy of the cerebral cortex that became prominent at 7 months after birth, with concomitant subdural effusions. Subdural effusions have only been reported in 1 previous case (5). Finally, a high DWI signal was detected in the genu and splenium of the corpus callosum at 7 months, concomitant with progressive white matter depletion. In previously reported cases, a high DWI signal was not described, whereas white matter depletion was present in almost all cases.

A total of 18 mutations in RARS2 have been identified in the previously reported cases, comprising of 11 missense mutations, one in-frame deletion, one substitution of nucleotide in the 5'-untranslated region that resulted in decreased mRNA expression level, and five mutations in introns. In the present case, two novel missense mutations in RARS2 were identified, c.1718C $>$ T(p.Thr573Ile) and c.991A $>$ G(p.Ile331Val) (Table I).

In conclusion, in the current study, two novel RARS2 mutations were identified in a patient with typical clinical manifestations of PCH6. Distinctive MRI features were identified, including pontocerebellar preservation after 1 year of age, as well as a high DWI signal suggestive of intracellular edema in the cerebellar hemispheres, basal ganglia, thalamus and corpus callosum. Furthermore, progressive loss of cerebral white matter and cortical volume were common features shared by all patients in similar previously reported cases, which were also observed in the present patient. Therefore, the findings reported in the present case enriched the phenotypic and genotypic spectrum of the RARS2 mutations in PCH6 patients.

\section{References}

1. Glamuzina E, Brown R, Hogarth K, Saunders D, Russell-Eggitt I, Pitt M, de Sousa C, Rahman S, Brown G and Grunewald S: Further delineation of pontocerebellar hypoplasia type 6 due to mutations in the gene encoding mitochondrial arginyl-tRNA synthetase, RARS2. J Inherit Metab Dis 35: 459-467, 2012.

2. Edvardson S, Shaag A, Kolesnikova O, Gomori JM, Tarassov I, Einbinder T, Saada A and Elpeleg O: Deleterious mutation in the mitochondrial arginyl-transfer RNA synthetase gene is associated with pontocerebellar hypoplasia. Am J Hum Genet 81: 857-862, 2007.

3. Rankin J, Brown R, Dobyns WB, Harington J, Patel J, Quinn M and Brown G: Pontocerebellar hypoplasia type 6: A British case with PEHO-like features. Am J Med Genet A 152A: 2079-2084, 2010.

4. Namavar Y, Barth PG, Kasher PR, van Ruissen F, Brockmann K, Bernert G, Writzl K, Ventura K, Cheng EY, Ferriero DM, et al: Clinical,neuroradiological and genetic findings in pontocerebellar hypoplasia. Brain 134: 143-156, 2011.

5. Kastrissianakis K, Anand G, Quaghebeur G, Price S, Prabhakar P, Marinova J, Brown G and McShane T: Subdural effusions and lack of early pontocerebellar hypoplasia in siblings with RARS2 mutations. Arch Dis Child 98: 1004-1007, 2013.

6. Cassandrini D, Cilio MR, Bianchi M, Doimo M, Balestri M, Tessa A, Rizza T, Sartori G, Meschini MC, Nesti C, et al: Pontocerebellar hypoplasia type 6 caused by mutations in RARS2: Definition of the clinical spectrum and molecular findings in five patients. J Inherit Metab Dis 36: 43-53, 2013.

7. Lax NZ, Alston CL, Schon K, Park SM, Krishnakumar D, He L, Falkous G, Ogilvy-Stuart A, Lees C, King RH, et al: Neuropathologic characterization of pontocerebellar hypoplasia type 6 associated with cardiomyopathy and hydrops fetalis and severe multisystem respiratory chain deficiency due to novel RARS2 mutations. J Neuropathol Exp Neurol 74: 688-703, 2015.

8. Li Z, Schonberg R, Guidugli L, Johnson AK, Arnovitz S, Yang S, Scafidi J, Summar ML, Vezina G, Das S, et al: A novel mutation in the promoter of RARS2 causes pontocerebellar hypoplasia in two siblings. J Hum Genet 60: 363-369, 2015.

9. Nishri D, Goldberg-Stern H, Noyman I, Blumkin L, Kivity S, Saitsu H, Nakashima M, Matsumoto N, Leshinsky-Silver E, Lerman-Sagie T and Lev D: RARS2 mutations cause early onset epileptic encephalopathy without ponto-cerebellar ypoplasia. Eur J Paediatr Neurol 20: 412-417, 2016.

10. Lühl S, Bode H, Schlötzer W, Bartsakoulia M, Horvath R, Abicht A, Stenzel M, Kirschner J and Grünert SC: Novel homozygous RARS2 mutation in two siblings without pontocerebellar hypoplasia- further expansion of the phenotypic spectrum. Orphanet J Rare Dis 11: 140, 2016.

11. Ngoh A, Bras J, Guerreiro R, Meyer E, McTague A, Dawson E, Mankad K, Gunny R, Clayton R, Mills PB, et al: RARS2 mutations in a sibship with infantile spasms. Epilepsia 57: e97-e102, 2016.

12. Li H and Durbin R: Fast and accurate long-read alignment with Burrows-Wheeler transform. Bioinforma 26: 589-595, 2010

13. McKenna A, Hanna M, Banks E, Sivachenko A, Cibulskis K, Kernytsky A, Garimella K, Altshuler D, Gabriel S, Daly M and DePristo MA: The Genome Analysis Toolkit: A MapReduce framework for analyzing next-generation DNA sequencing data. Genome Res 20: 1297-1303, 2010.

14. Wang K, Li M and Hakonarson H: ANNOVAR: Functional annotation of genetic variants from high-throughput sequencing data. Nucleic Acids Res 38: e164, 2010.

15. Lek M, Karczewski KJ, Minikel EV, Samocha KE, Banks E, Fennell T, O'Donnell-Luria AH, Ware JS, Hill AJ, Cummings BB, et al: Analysis of protein-coding genetic variation in 60,706 humans. Nature 536: 285-291, 2016.

16. Richards S, Aziz N, Bale S, Bick D, Das S, Gastier-Foster J, Grody WW, Hegde M, Lyon E, Spector E, et al: Standards and guidelines for the interpretation of sequence variants: A joint consensus recommendation of the American College of Medical Genetics and Genomics and the Association for Molecular Pathology. Genet Med 17: 405-424, 2015. 